\title{
Heritability of body mass varies with age and season in wild bighorn sheep
}

\author{
DENIS RÉALE* $\uparrow$, MARCO FESTA-BIANCHET $\uparrow \&$ JON T. JORGENSON $\ddagger$ \\ $\uparrow$ Département de Biologie, Université de Sherbrooke, Sherbrooke, Québec, Canada J1K $2 R 1$ and \\ $\$$ Department of Environmental Protection, Alberta Natural Resources Service, Suite 201, \\ 800 Railway Avenue, Canmore, Alberta, Canada T1W 1P1
}

\begin{abstract}
Heritabilities $\left(h^{2}\right)$ of body mass at different ages and seasons were estimated using offspring-mother regression and restricted maximum likelihood (REML) methods for bighorn sheep on Ram Mountain, Alberta. Both methods resulted in similar estimates of $h^{2}$ for adults, but for lambs and yearlings heritability was underestimated by offspring-mother regression relative to REML, possibly because of higher maternal-effects bias for offspring-mother regression. Heritabilities of body mass in bighorn were similar to published estimates for domestic sheep. Heritability estimated by offspringmother regression increased after 2 years of age. The REML method suggested that heritability was moderate for lambs and yearlings, very low at 2 years of age, and increased afterwards. The increase in heritability with age was attributed to declining negative maternal effects. Very low $h^{2}$ estimates at 2 years of age, obtained with both methods, appeared to be caused by a combination of high environmental variance and very low genetic variance. Body mass of bighorn sheep has a pronounced seasonal cycle, and $h^{2}$ was lower in June than in September for 2-year-olds and older sheep, and associated with both lower $V_{\mathrm{A}}$ and higher $V_{\mathrm{E}}$ in spring.
\end{abstract}

Keywords: body mass, genetic variance, heritability, mammals, Ovis canadensis, REML.

\section{Introduction}

Evolutionary changes in quantitative traits in natural populations depend on the magnitude of heritability of each trait and on the genetic correlations between traits (Lande, 1979; Falconer \& Mackay, 1996; Roff, 1997; Lynch \& Walsh, 1998). Quantitative genetic studies applied to evolutionary biology and ecology have recently multiplied (Roff, 1997; Lynch \& Walsh, 1998). However, although there are numerous published studies of the quantitative genetics of plants, invertebrates and small vertebrates (Roff, 1997), studies of large wild mammals are rare (Cheverud \& Dittus, 1992).

Here we provide the first estimate of the heritability of body mass at different ages for a wild large mammal, using a unique long-term data set on marked bighorn sheep (Ovis canadensis). We chose body mass because it affects many life-history traits of this species, including survival (Festa-Bianchet et al., 1997), longevity (Bérubé et al., 1999) and female reproductive success (FestaBianchet et al., 1998).

*Correspondence. E-mail: denis.reale@courrier.usherb.ca
Cheverud \& Moore (1994) underlined the important contribution to quantitative genetics that could be made by studies in behavioural ecology based upon long-term monitoring of marked individuals. However, wild animals are normally difficult to capture, and because juveniles often have low survival, very few studies have accumulated the sample size necessary to estimate quantitative genetic parameters reliably (Klein et al., 1973). One could measure quantitative traits in the captive-reared offspring of wild-caught parents, but there are serious questions about the reliability of laboratory estimates of heritability (Riska et al., 1989; Simons \& Roff, 1994; but see Weigensberg \& Roff, 1996). In addition, only a narrow taxonomic range of species is suitable for laboratory study: long-lived and large mammals are seldom reared in captivity in sufficient numbers. Consequently, heritability studies of large mammals have been restricted to domestic species (Snyman et al., 1995; Näsholm \& Danell, 1996) or to wild species in captivity (Williams et al., 1994; Jaquish et al., 1997; Vandenberg \& Garrick, 1997).

An additional obstacle to studies of heritability in large mammals is the difficulty experienced in determining paternity. In many polygynous or promiscuous mammals, paternity can only be determined by molecular methods (Hogg \& Forbes, 1997). Nevertheless, 
estimates of heritability can be obtained with motheroffspring relationships or with Restricted Maximum Likelihood (REML) methods that take into account all the genetic relationships available within an incomplete pedigree (Cheverud \& Dittus, 1992; Konigsberg \& Cheverud, 1992; Cheverud \& Moore, 1994).

Because opportunities to recapture wild animals are rare, most field studies cannot obtain age-specific measures of morphological traits. Measurements are therefore adjusted to some average age to increase sample size for quantitative genetic analyses (Cheverud \& Dittus, 1992; Konigsberg \& Cheverud, 1992). Heritability of a trait, however, may change with age (Rutledge et al., 1972; Cheverud et al., 1983) and therefore information may be lost by adjustments to a common age. Because almost all of our study animals were captured repeatedly each year, we were able to analyse how heritability of body mass varies with age in a long-lived mammal.

Different environmental conditions may also affect heritability of a trait (Hoffmann \& Parsons, 1991; Falconer \& Mackay, 1996). For example, in temperate ungulates, mass varies greatly according to season (Festa-Bianchet et al., 1996). Annual fluctuations in body mass are associated with adaptive seasonal changes in metabolic rate and food requirements (Suttie \& Webster, 1995), but could also be affected by weather and by food availability. Because in most field studies it is not possible to measure animals at different times of the year, little is known about seasonal variation in heritability of morphological traits. Therefore, we examined how estimates of heritability of body mass may vary seasonally in bighorn sheep. We expected that heritability of body mass would be greater in September than in June: an individual's mass can vary by as much as $35 \%$ over a year, and September body mass appears to be less influenced by environmental factors than June mass (Festa-Bianchet et al., 1996).

\section{Materials and methods}

The bighorn sheep population at Ram Mountain, Alberta $\left(52^{\circ} \mathrm{N}, 115^{\circ} \mathrm{W}\right.$; elevation $\left.1082-2173 \mathrm{~m}\right)$ has been studied since 1971. Data used in this paper were collected between 1973 and 1997. Until 1981, ewe removals kept the population stable at 30-33 adult ewes. After removals were ended in 1981, the population increased, peaked at 104 ewes in 1992, then declined to 75 ewes by 1997 .

In most years, over $80 \%$ of the lambs that survived to a few weeks of age were captured and marked before October. All unmarked lambs that survived the winter were marked the following year as yearlings, but at that age their mothers could no longer be identified. Each summer, adult sheep were captured two to six times and weighed to the nearest $125 \mathrm{~g}$ with a Detecto spring scale. Body mass of individual sheep was adjusted using each individual's own rate of mass gain obtained from multiple captures. The adjustment dates were 5 June (spring mass: sheep probably started gaining mass in May) and 15 September (autumn mass: by mid-September adult ewes were near their peak yearly mass). FestaBianchet et al. (1996) provide more details on the capture schedule and mass adjustments. Lambs were more difficult to capture than older sheep, therefore for those captured only once we adjusted mass using the mean rate of mass accumulation for lambs of the same sex weighed at least twice in that same year. Lamb spring mass was adjusted to 15 June instead of 5 June, because few lambs were caught before 5 June and in some years some lambs were born in early June.

Mother-lamb relationships were determined by observing marked lambs repeatedly suckling from marked females from May to October. Allosuckling has never been observed on Ram Mountain. Fathers are unknown in this population, therefore we could not estimate heritability by using sire-offspring relationships. Previous studies on dimorphic mammals have shown that heritability estimated without fathers did not greatly differ from heritability estimates when fathers were considered (Konigsberg \& Cheverud, 1992), and that the heritability of body mass is similar for both sexes (Vandenberg \& Garrick, 1997). Ewes always produced singleton lambs, therefore common maternal environmental effects on heritability should be reduced. Common environmental effects on heritability estimates would be very limited, because bighorns are philopatric, do not form kin groups and all ewes in the population use the same home range (Festa-Bianchet, 1991), decreasing the possibility that a common early environment would have different effects on different family groups.

Heritability $\left(h^{2}\right)$ was estimated for body mass in spring and autumn for lambs, yearlings, 2-, 3- and 4 -year-olds, and adults (the average of all seasonally adjusted mass measurements for each individual between 5 and 11 years of age). Estimates were obtained by regressing the mean values for offspring at a given age on maternal values at the same age (Falconer \& Mackay, 1996). Heritability was calculated as twice the slope of the regression, and the standard error is twice the standard error of the slope (Falconer \& Mackay, 1996). Analyses were performed with both sexes pooled, to compare our results with studies on domestic sheep that always report heritability estimates for both sexes pooled (Snyman et al., 1995; Näsholm \& Danell, 1996). To obtain more accurate heritability estimates we controlled statistically for environmental effects on phenotypic variance. To account for sexual dimorphism, data were standardized by subtracting each individual's 
mass from the mean mass of its sex-age class and by dividing it by the standard deviation (Lynch \& Walsh, 1998). We then used year-specific residuals of body mass, to eliminate between-year variations in body mass. These adjustments partly accounted for yearly environmentally induced variability in body mass, but not for potential effects of genotype-environment interactions. Because we used the same individuals to estimate heritability at different ages, our analyses may suffer to an unknown extent from nonindependence of data, therefore we do not present statistical tests comparing heritability at different ages. Statistics were performed with STATVIEW (Abacus Concepts, 1992).

Heritabilities were also estimated with an animal model by Derivative Free Restricted Maximum Likelihood (DFREML 3.0; Meyer, 1989, 1997). This method uses all the available kin relationships within a pedigree (Shaw, 1987; Meyer, 1989) and constrains heritability to between 0 and 1 (Meyer, 1989). The REML method can also partition the phenotypic variance $V_{\mathrm{P}}$ of a quantitative character into $V_{\mathrm{A}}, V_{\mathrm{E}}$ and other effects such as maternal, common environmental, or permanent environmental effects (Meyer, 1989). Pedigrees were built based on known mother-lamb relationships. Because sires were unknown, fathers were coded as ' 0 ' in the pedigrees. We analysed mass records separately according to season and age. For sheep up to 4 years of age, univariate models were fitted with:

$\mathbf{y}=\mathbf{X b}+\mathbf{Z} \mathbf{a}+\mathbf{e}$,

where $\mathbf{y}$ is the mass record; $\mathbf{b}$ and $\mathbf{a}$ are the vectors of fixed and random additive effects; $\mathbf{X}$ and $\mathbf{Z}$ are the corresponding incidence matrices relating the effects to $\mathbf{y}$; and $\mathbf{e}$ is the vector of residuals. The fixed part of the model included sex and years. The convergence criterion was set to $10^{-8}$.

For sheep aged 5-11 years, between one and seven records were available for each individual depending on its age at death or in 1997 (the last year of data collection, when some animals were still alive). We therefore fitted two models to the data for sheep aged 5-11 years: the univariate model presented above and one including permanent environmental effects:

$\mathbf{y}=\mathbf{X b}+\mathbf{Z}_{\mathbf{1}} \mathbf{a}+\mathbf{Z}_{\mathbf{2}} \mathbf{m}+\mathbf{e}$,

where all parameters were as defined above, and $\mathbf{m}$ was the vector of individual permanent environmental effects associated with the incidence matrix $\mathbf{Z}_{\mathbf{2}}$. The fixed part of the model included sex and years, and age was included as a covariable. The convergence criterion was set to $10^{-8}$. The program estimates $V_{\mathrm{A}}, V_{\mathrm{E}}, V_{\mathrm{P}}, V_{\mathrm{M}}, h^{2}$ and $m^{2}$ (Meyer, 1997).
Heritability was estimated as

$h^{2}=V_{\mathrm{A}} / V_{\mathrm{P}}$

Repeatability was calculated for adults only as

$r=\left(V_{\mathrm{A}}+V_{\mathrm{M}}\right) / V_{\mathrm{P}}$.

For sheep aged 5-11 years, models with and without permanent environmental effects were compared using likelihood ratio tests (Shaw, 1987). The difference between likelihood functions ( -2 [log likelihood Model $1-\log$ likelihood Model 2]) of each model is assumed to follow a chi-squared distribution with degrees of freedom equal to the difference in parameters between the two models (here d.f. $=1$ ).

\section{Results}

The number of families used in offspring-mother regressions ranged from 60 to 101, with mean number of offspring per ewe between 1.53 and 2.52 (Table 1). Heritability estimates with offspring-mother regressions ranged from -0.15 to 0.59 depending on age and season (Table 1). Heritability estimates before 3 years of age were not significantly different from 0 . Estimates differed significantly from 0 for body mass in September for 4-year-olds and in June and September for sheep aged 5-11 years. After 3 years of age, there was a consistent trend for higher heritability in September than in June.

The data used for the REML analyses are summarized in Table 2. Body mass of sheep increased with age and was higher in September than in June for all age classes (Festa-Bianchet et al., 1996). The number of animals with records and number of dams with progeny records decreased with age.

For June mass of sheep aged 5-11 years, the inclusion of a permanent environmental effect significantly improved the fit of the model (likelihood ratio test; $\left.\chi_{1}^{2}=4.855, P<0.05\right)$. The permanent environmental effect was equal to $0.35 \pm 0.17$ (SE), and repeatability was 0.63 (Table 3). A model without permanent environmental effect, however, provided the best estimate of the heritability of body mass adjusted to 15 September, according to a likelihood ratio test $\left(\chi_{1}^{2}=1.673\right.$, $P>0.05)$. Phenotypic variance $\left(V_{\mathrm{P}}\right)$ increased with age. Additive genetic variance $\left(V_{\mathrm{A}}\right)$ ranged from 0.044 to 31.497 (Table 3). $V_{\mathrm{A}}$ was moderate for lambs and yearlings, very low for 2-year-olds, and increased afterwards. Environmental variance $\left(V_{\mathrm{E}}\right)$ first increased with age, peaking in September at age 2, then decreased. Heritability estimates ranged from 0 to 0.81 depending on age and season. Estimates differed significantly from 
Table 1 Heritability estimates of body mass in the Ram Mountain bighorn sheep population, based on mean offspringmother regressions

\begin{tabular}{llcccc}
\hline Age class & Month & $n_{\mathrm{f}}$ & $n_{\mathrm{o}}$ & $h^{2} \pm \mathrm{SE}$ & $P$ \\
\hline Lambs & June & 66 & $2.52 \pm 1.51$ & $0.00 \pm 0.18$ & 0.99 \\
& September & 73 & $2.51 \pm 1.75$ & $0.02 \pm 0.19$ & 0.92 \\
Yearling & June & 94 & $1.99 \pm 1.21$ & $0.12 \pm 0.20$ & 0.55 \\
& September & 76 & $1.92 \pm 1.06$ & $0.07 \pm 0.17$ & 0.68 \\
2-year-old & June & 101 & $1.81 \pm 1.09$ & $-0.15 \pm 0.15$ & 0.30 \\
& September & 80 & $1.68 \pm 0.97$ & $-0.09 \pm 0.18$ & 0.60 \\
3-year-old & June & 82 & $1.89 \pm 1.09$ & $0.28 \pm 0.17$ & 0.11 \\
& September & 71 & $1.68 \pm 1.04$ & $0.49 \pm 0.23$ & 0.04 \\
4-year-old & June & 72 & $1.90 \pm 1.04$ & $0.26 \pm 0.18$ & 0.14 \\
& September & 60 & $1.53 \pm 0.85$ & $0.59 \pm 0.19$ & 0.003 \\
Adult (5-11 yr) & June & 77 & $1.92 \pm 1.18$ & $0.39 \pm 0.18$ & 0.04 \\
& September & 65 & $1.69 \pm 0.98$ & $0.57 \pm 0.18$ & 0.003 \\
\hline
\end{tabular}

Male and female offspring are pooled for the analyses, and mass is standardized according to sex and year.

Estimates for adults were obtained from the individual mean mass from 5 to 11 years of age.

$n_{\mathrm{f}}$, number of families; $n_{\mathrm{o}}$, mean number of offspring per family $( \pm \mathrm{SD})$.

Table 2 Body mass (kg) in the Ram Mountain bighorn sheep population, standardized according to sex and adjusted to 5 June and 15 September at different ages

\begin{tabular}{llccr}
\hline Age class & Month & Mean \pm SD & $N r$ & Dams \\
\hline Lambs & June & $9.09 \pm 2.57$ & 378 & 108 \\
& September & $27.05 \pm 4.65$ & 444 & 125 \\
Yearling & June & $30.29 \pm 4.87$ & 330 & 102 \\
& September & $47.76 \pm 7.06$ & 295 & 87 \\
2-year-old & June & $44.06 \pm 7.02$ & 295 & 104 \\
& September & $61.70 \pm 9.34$ & 252 & 83 \\
3-year-old & June & $52.81 \pm 9.28$ & 259 & 83 \\
& September & $67.09 \pm 9.03$ & 192 & 62 \\
4-year-old & June & $59.71 \pm 11.94$ & 220 & 67 \\
& September & $69.72 \pm 9.61$ & 153 & 56 \\
Adult (5-11 yr) & June & $61.46 \pm 11.76$ & $712(222)$ & 84 \\
& September & $72.80 \pm 8.44$ & $563(171)$ & 68 \\
\hline
\end{tabular}

$N r$, number of records used in REML analyses. The number of animals with records is equal to $N r$ except for adults, where several individuals were sampled at different ages and the number of individual sheep with records is indicated in parentheses.

Dams, number of dams with progeny records (sires are unknown) in REML analyses.

0 for lambs in both seasons, yearlings in June, and for 3and 5-11-year-old sheep in September. Lack of significance for some age classes was possibly caused by high standard errors associated with heritability estimates. Heritabilities were moderate for lambs and yearlings. The low heritabilities at 2 years of age were associated with very low $V_{\mathrm{A}}$. Heritability estimates increased for older age classes (Table 3). Estimates of heritability were higher in June than in September for yearlings, but from 3 years of age onwards, estimates were higher in September than in June.

\section{Discussion}

Heritability of body mass is not negligible and varies with age and season for the Ram Mountain bighorn sheep population. Because of small sample sizes, the standard errors of heritability estimates were high. Consequently, heritability estimates could be shown to be significantly different from zero only when they were high (Klein et al., 1973).

Depending on the method, heritabilities were low to moderate for lambs (Tables 1 and 3). Heritabilities of

(C) The Genetical Society of Great Britain, Heredity, 83, 526-532. 
Table 3 Estimates of covariance components of body mass in June and September for bighorn sheep of different ages at Ram Mountain, Alberta

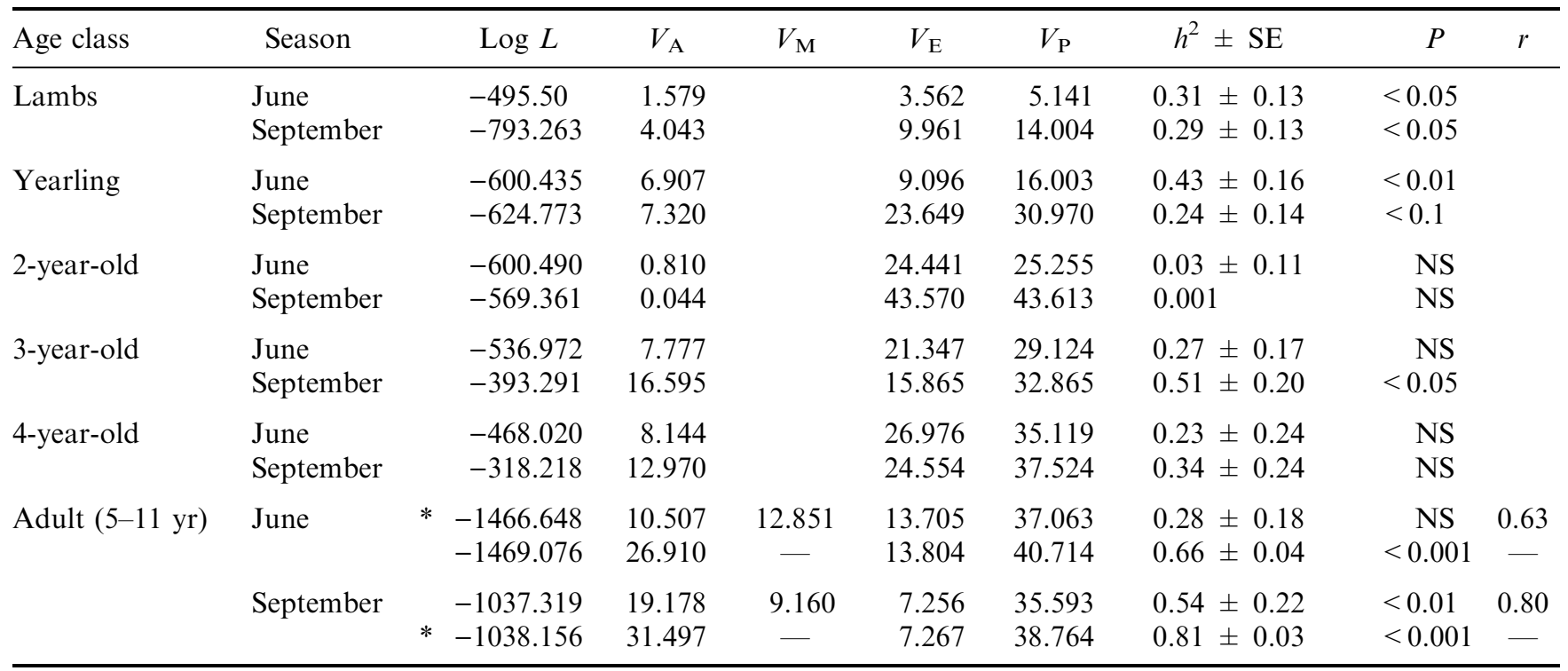

$\log L, \log$ likelihood; $V_{\mathrm{A}}$, additive genetic variance; $V_{\mathrm{E}}$, environmental variance; $V_{\mathrm{P}}$, phenotypic variance; $h^{2}$, heritability $( \pm$ approximate $\mathrm{SE}$ ). For adults, two models with and without permanent environmental effects are shown. In the model including permanent effects $V_{\mathrm{M}}$ refers to the individual permanent environmental variance $( \pm \mathrm{SE})$ and $r$ to the repeatability. *Indicates the best model according to the likelihood ratio test (see text for further explanation). SE of heritability at 2 years of age in September could not be estimated because the maximization process did not converge successfully.

birth and weaning mass in domestic sheep vary considerably among breeds (total heritability: $0.04-0.39$ for birth mass and 0.09-0.52 for weaning mass (Snyman et al., 1995). Differences in lamb birth date, which were not considered in this study, increase phenotypic variance of body mass (Bérubé, 1997). Births occur later at high population density (Festa-Bianchet, 1988), and differences in birth date probably decreased the heritability estimate of lamb body mass, because relatives were born at different times. Heritability was also low to moderate for yearlings. Our REML estimate at 12 months of age (0.43) is within the range of 0.28 0.48 reported by Snyman et al. (1995). For lambs and yearlings, estimates with offspring-mother regression were lower than those obtained with REML (Tables 1 and 3). REML estimates may be less sensitive to maternal effects because they take into account pedigree relationships other than mother-offspring (see below). For sheep 2 years of age and older, both methods produced similar heritability estimates. Heritabilities were very low for 2-year-olds and increased thereafter (Tables 1 and 3). Our estimates were similar to or higher than the few published heritability estimates of mass for mature domestic sheep, that vary between 0.3 and 0.5 (reviewed in Näsholm \& Danell, 1996).

The low heritability of mass at 2 years of age is probably caused by high environmental variance resulting from individual differences in reproductive status at that age (Jorgenson et al., 1993). Reproduction at 2 years of age affects body mass (Festa-Bianchet et al., 1995). However, REML estimates also suggested very low additive genetic variance in body mass at 2 years of age. Traits closely related to fitness generally have low additive genetic variance and heritability (Fisher, 1930; Gustaffson, 1986; Mousseau \& Roff, 1987). Body mass at 2 years of age may be highly related to fitness at Ram Mountain, or may be genetically correlated with other traits related to fitness, such as reproductive maturity or lifetime reproductive success (Lande, 1979).

Mother-offspring estimates of heritability increased with age, although REML estimates were moderate before 2 years of age, very low for 2-year-olds and increased thereafter (Tables 1 and 3). To our knowledge, no age-specific heritability estimates are available for other wild ungulates, but an increase in heritability of body mass with age has been shown in domestic sheep (Näsholm \& Danell, 1996; Yazdi et al., 1997). The increase in heritability of morphological characters during ontogeny is generally associated with declining maternal effects with age (Rutledge et al., 1972; Cheverud et al., 1983; Cheverud, 1984). In most mammals, the direct-maternal genetic correlations vary with age, being positive and moderate soon after birth, then becoming strongly negative near the time of weaning, and positive afterwards (Cheverud, 1984). Because fathers were unknown, the number of different types of kin 
relationships in the pedigree was insufficient to precisely estimate maternal effects and direct-maternal genetic correlations (Meyer, pers. comm.). However, two lines of evidence suggest that maternal effects explained some of the variation in heritability with age. First, as indicated before, heritabilities were underestimated by the mother-offspring regression compared to REML, suggesting the presence of negative maternal effects early in life. Secondly, the phenotypic correlation of maternal and offspring mass is very weak (Festa-Bianchet \& Jorgenson, 1998), suggesting that small females have a higher level of maternal expenditure than large females, which allows the lambs of small females to reach a greater weaning mass than that which may be set by genetic effects alone. As individuals aged, maternal effects probably decreased and additive genetic variance accounted for a greater proportion of the phenotypic variation in body mass (Table 3 ).

For sheep older than 2 years, heritability of body mass was lower in June than in September. Three different reasons have been proposed to explain differences in heritability depending on environmental conditions (Hoffmann \& Parsons, 1991; Falconer \& Mackay, 1996; Merilä, 1997). First, low $V_{\mathrm{A}}$ should be responsible for lower heritability under poor environmental conditions. Secondly, $V_{\mathrm{E}}$ should increase under poor environmental conditions. Thirdly, the genetic correlation between measures of a trait in the two environments should be less than one, indicating a genotype-environment interaction. In our study, lower heritability in June compared to September corresponded to a decrease in $V_{\mathrm{A}}$ and an increase in $V_{\mathrm{E}}$, as observed in other empirical studies (Simons \& Roff, 1994; Merilä, 1997). In the highly seasonal climate of Ram Mountain, sheep have greater control over their summer mass gain than over their winter mass loss (Festa-Bianchet et al., 1996). Predictable and plentiful summer forage may limit environmental effects on variation of body mass in September. On the other hand, harsh winter weather may affect forage availability or increase thermoregulatory costs in an unpredictable way (Festa-Bianchet et al., 1996), and lower the heritability of mass in early June. Environmental variation has been shown to influence quantitative genetic parameters in birds for individuals that have grown under different environmental conditions (Van Noordwijk et al., 1988; Larsson, 1993; Merilä, 1997), but most of those comparisons involved skeletal measures that do not change in adults. Our results show that heritability of a trait can also differ when estimated from the same set of individuals measured at different seasons, regardless of age. Heritability of traits that are phenotypically plastic is sensitive to heterogeneous environmental conditions (Riska et al., 1989; Simons \& Roff, 1994; Weigensberg \& Roff, 1996).
In conclusion, the results of this study underline the value of long-term monitoring of natural populations for quantitative genetic studies. REML methods of variance component estimates offer good opportunities to study natural populations where experimental controlledbreeding designs are impractical and where families are of unequal size. The quantitative genetic approach is a promising avenue for studies of behavioural ecology because it can estimate the evolutionary potential or previous selection processes for complex traits. Our results caution that factors such as season and age should be accounted for in heritability estimates.

\section{Acknowledgements}

We thank the many people who trapped and weighed sheep over the last 25 years. D.A. Roff provided advice, encouragement and comments on a previous draft of the paper. K. Meyer kindly allowed us to use her software DFREML 3.0 and helped with the use of REML. J.W. Shipley and S. Demers provided statistical advice. D. Réale was supported by a postdoctoral fellowship from the Fyssen foundation (France). Financial support for the Ram Mountain bighorn research was generously provided by the Natural Sciences and Engineering Research Council of Canada, the Alberta Natural Resources Service, The Foundation for North American Wild Sheep, the Université de Sherbrooke and the Fonds FCAR (Québec). This is contribution number 129 of the Groupe de recherche en écologie, nutrition et énergétique.

\section{References}

ABACUS CONCEPTS INC. 1992. STATVIEW 4.02. Berkeley, CA. BÉRUBÉ, C. H. 1997. Les stratégies d'adaptation vitale chez les brebis du mouflon d'Amérique (Ovis canadensis): la reproduction en fonction de l'âge. Ph.D. Thesis, Université de Sherbrooke, Canada.

BÉRUBÉ, C. H., FESTA-BIANCHET, M. AND JORGENSON, J. T. 1999. Individual differences and reproductive senescence in bighorn ewes. Ecology, 80, in press.

CHEVERUD, J. M. 1984. Evolution by kin selection: a quantitative genetic model illustrated by maternal performance in mice. Evolution, 38, 766-777.

CheVerud, J. M. AND DitTUS, P. J. 1992. Primate population studies at Polonnaruwa. II. Heritability of body measurements in a natural population of toque macaques (Macaca sinica). Am. J. Primatol., 27, 145-156.

CHEVERUd, J. M. AND MOORE, A. J. 1994. Quantitative genetics and the role of the environment provided by relatives in behavioral evolution. In: Boake, C. R. B. (ed.) Quantitative Genetic Studies of Behavioral Evolution, pp. 67-100. University of Chicago Press, Chicago, IL.

Cheverud, J. M., RUtLedGe, J. J. AND ATChley, W. R. 1983. Quantitative genetics of development: genetic correlation

(C) The Genetical Society of Great Britain, Heredity, 83, 526-532. 
among age-specific trait values and the evolution of ontogeny. Evolution, 37, 895-905.

FALCONER, D. S. AND MACKAY, T. F. C. 1996. Introduction to Quantitative Genetics, 4th edn. Longman, New York.

FESTA-BIANCHET, M. 1988. Birthdate and survival in bighorn lambs (Ovis canadensis). J. Zool., 214, 653-661.

FESTA-BIANCHET, M. 1991. The social system of bighorn sheep: grouping patterns, kinship and female dominance rank. Anim. Behav., 42, 71-82.

FESTA-BIANCHET, M. AND JORGENSON, J. T. 1998. Selfish mothers: reproductive expenditure and resource availability in bighorn ewes. Behav. Ecol., 9, 144-150.

FESTA-BIANCHET, M., JORGENSON, J. T., LUCHERINI, M. AND WISHART, W.D. 1995. Life history consequences of variation in age of primiparity in bighorn ewes. Ecology, 76, 871-881.

FESTA-BIANCHET, M., JORGENSON, J. T., KING, W. J., SMITH, K. G. AND WISHART, w. D. 1996. The development of sexual dimorphism: seasonal and lifetime mass changes in bighorn sheep. Can. J. Zool., 74, 330-342.

FESTA-BIANCHET, M., JORGENSON, J. T., BÉRUbÉ, C., PORTIER, C. AND WISHART, w. D. 1997. Body mass and survival in bighorn sheep. Can. J. Zool., 75, 1372-1379.

FESTA-BIANCHET, M., GAILLARD, J. M. AND JORGENSON, J. T. 1998. Mass- and density-dependent reproductive success and reproductive costs in a capital breeder. Am. Nat., 152, 367-379.

FISHER, R. A. 1930. The Genetical Theory of Natural Selection. Clarendon Press, Oxford.

GUSTAFFSON, L. 1986. Lifetime reproductive success and heritability: empirical support for Fisher's fundamental theorem. Am. Nat., 128, 761-764.

HOFFMANN, A. A. AND PARSONS, P. A. 1991. Evolutionary Genetics and Environmental Stress. Oxford University Press, Oxford.

HOGG, J. T. AND FORBES, S. H. 1997. Mating in bighorn sheep: frequent male reproduction via a high-risk 'unconventional' tactic. Behav. Ecol. Sociobiol., 41, 33-48.

JAQUiSh, C. E., DYER, T., WILlIAMS-BlANGERO, S., DYKe, B., LELAND, M. AND BLANGERO, J. 1997. Genetics of adult body mass and maintenance of adult body mass in captive baboons (Papio hamadryas subspecies). Am. J. Primatol., 42, 281-288.

JORGENSON, J. T., FESTA-BIANCHET, M., LUCHERINI, M. AND WISHART, W. D. 1993. Effects of body size, population density, and maternal characteristics on age at first reproduction in bighorn ewes. Can. J. Zool., 71, 2509-2517.

KLEIN, T. W., DE FRIES, J. C. AND FINKBEINER, C. T. 1973. Heritability and genetic correlation: standard errors of estimates and sample size. Behav. Genet., 3, 355-364.

KONIGSBERG, L. AND CHEVERUD, J. 1992. Uncertain paternity in primate quantitative genetic studies. Am. J. Primatol., 27, 133-143.

LANDE, R. 1979. Quantitative genetic analysis of multivariate evolution applied to brain:body size allometry. Evolution, 33, 402-416.

LARSSON, K. 1993. Inheritance of body size in the barnacle goose under different environmental conditions. J. Evol. Biol., 6, 195-208.
LYNCH, M. AND WALSH, B. 1998. Genetic Analysis of Quantitative Traits. Sinauer Associates, Sunderland, MA.

MERILÄ, J. 1997. Expression of genetic variation in body size of the collared flycatcher under different environmental conditions. Evolution, 51, 526-536.

MEYER, K. 1989. Restricted maximum likelihood to estimate variance components for animal models with several random effects using a derivative-free algorithm. Génét. Sél. Évol., 21, 317-340.

MEYER, K. 1997. DFREML: programs to estimate variance components by restricted maximum likelihood using a derivative-free algorithm. User notes, version $3.0 \alpha$. Available through the DFREML home page, http: //agbu.une.edu/ kmeyer/dfreml.html.

MOUSSEAU, T. A. AND ROFF, D. A. 1987. Natural selection and the heritability of fitness components. Heredity, 59, 181-198.

NÄSHOLM, A. AND DANELL, Ö. 1996. Genetic relationships of lamb weight, maternal ability, and mature ewe weight in Swedish finewool sheep. J. Anim. Sci., 74, 329-339.

RISKA, B., PROUT, T. AND TURELLI, M. 1989. Laboratory estimates of heritabilities and genetic correlations in nature. Genetics, 123, 865-871.

ROFF, D. A. 1997. Evolutionary Quantitative Genetics. Chapman \& Hall, New York.

RUTLEDGE, J. J., ROBINSON, O. W., EISEN, E. J. AND LEGATES, J. E. 1972. Dynamics of genetic and maternal effects in mice. J. Anim. Sci., 35, 911-918.

SHAw, R. 1987. Maximum-likelihood approaches applied to quantitative genetics in natural population. Evolution, 41, $812-826$

SIMONS, A. M. AND ROFF, D. A. 1994. The effects of environmental variability on the heritabilities of traits of a field cricket. Evolution, 48, 1367-1379.

SNYMAN, M. A., ERASMUS, G. J., VAN WIK, J. B. AND OLIVIER, J. J. 1995. Direct and maternal (co)variance components and heritability estimates for body weight at different ages and fleece traits in Afrino sheep. Livest. Prod. Sci., 44, 229-235.

SUTTIE, J. M. AND WEBSTER, J. R. 1995. Extreme seasonal growth in Arctic deer: comparisons and control mechanisms. Am. Zool., 35, 215-221.

VAN NOORDWIJK, A. J., VAN BALEN, J. H. AND SCHARLOO, w. 1988. Heritability of body size in a natural population of the great tit (Parus major) and its relation to age and environmental condition during growth. Genet. Res., 51, 149-162.

VANDENBERG, G. H. J. AND GARRICK, D. J. 1997. Inheritance of adult velvet antler weights and live weights in farmed red deer. Livest. Prod. Sci., 49, 287-295.

WEIGENSBERG, I. AND ROFF, D. A. 1996. Natural heritabilities: can they be reliably estimated in the laboratory? Evolution, 50, 2149-2157.

WILliAMS, J. D., KRUEGER, W. F. AND HARMEL, D. H. 1994. Heritabilities for antler characteristics and body weight in yearling white-tailed deer. Heredity, 73, 78-83.

YAZDI, M. H., ENGSTROM, G., NÄSHOLM, A., JOHANSSON, K., JORJANI, H. AND LILJEDAHL, L. E. 1997. Genetic parameters for lamb weight at different ages and wool production in Baluchi sheep. Anim. Sci., 65, 247-255. 